\title{
Perencanaan Instalasi Pengolahan Air Limbah (IPAL) Cair Peternakan Sapi Pada Desa Petungsewu Kecamatan Dau Kabupaten Malang Menggunakan Filtrasi dan Biofilter Anaerob
}

\section{Bagas Kusdiyatno Wardana ${ }^{1 *}$, Riyanto Haribowo ${ }^{1}$, Emma Yuliani $^{1}$}

${ }^{1}$ Jurusan Teknik Pengairan, Fakultas Teknik, Universitas Brawijaya, Jl. MT. Haryono No. 167, Malang, 65145, Indonesia

*Korespondensi Email: bagaskwardana@gmail.com

\begin{abstract}
In Malang Regency, especially Petungsewu Village, there is no single Wastewater Treatment Plant (WWTP) can be found that specifically treats cattle wastewater. Therefore, purpose of this study is to figure out the most effective WWTP model for treating cattle wastewater. Located in Petungsewu Village, a farm with 14 cows. The discharge of wastewater reaches $1,071 \mathrm{~m}^{3} /$ day. The quality of wastewater uses parameters that refer to the Peraturan Menteri Lingkungan Hidup (Permen. LHK) Nomor 11 tahun 2009, namely BOD, COD, TSS, NH3-N, and pH. After laboratory tests, each was $64,27 \mathrm{mg} / \mathrm{l} ; 201,4 \mathrm{mg} / \mathrm{l} ; 100,1 \mathrm{mg} / \mathrm{l} ; 66,02 \mathrm{mg} / \mathrm{l} ;$ and 8,35. Based on the data on the quantity and quality of wastewater above, the WWTP method approach was carried out using 3 alternatives, those are filtration, anaerobic biofilter, and combination methods. Each alternative achieves an effluent reduction efficiency of up to $92,26 \%$. The planned budget (RAB) for the operation and building of the WWTP is IDR 13.702.933.
\end{abstract}

Keywords: Biofilter Method, Cattle Wastewater, Filtration Method, WWTP.

Abstrak: Di Kabupaten Malang khususnya Desa Petungsewu, belum terdapat satu pun Instalasi Pengolahan Air Limbah (IPAL) yang secara spesifik mengolah limbah cair peternakan. Maka dari itu penelitian ini bertujuan untuk mencari model IPAL yang paling efektif untuk mengolah limbah cair peternakan sapi. Berlokasi di Desa Petungsewu, sebuah peternakan dengan sapi berjumlah 14 ekor. Limbah cair yang dihasilkan mencapai $1,071 \mathrm{~m}^{3} /$ hari. Kualitas air limbah menggunakan parameter yang mengacu ke Peraturan Menteri Lingkungan Hidup (Permen. LHK) Nomor 11 Tahun 2009 yakni BOD, COD, TSS, NH3-N, dan pH. Setelah uji laboratorium, masingmasing nilainya sebesar $64,27 \mathrm{mg} / \mathrm{l} ; 201,4 \mathrm{mg} / \mathrm{l} ; 100,1 \mathrm{mg} / \mathrm{l} ; 66,02 \mathrm{mg} / \mathrm{l} ;$ dan 8,35. Berdasarkan data kuantitas dan kualitas air limbah di atas, dilakukan pendekatan metode IPAL menggunakan 3 alternatif yakni filtrasi, biofilter anaerob, dan metode kombinasi. Masing-masing alternatif mencapai efisiensi pengurangan efluen hingga 92,26\%. Rencana Anggaran Biaya (RAB) untuk operasional dan bangunan IPAL adalah Rp13.702.933.

Kata kunci: IPAL, Limbah Cair Peternakan, Metode Biofilter, Metode Filtrasi. 


\section{Pendahuluan}

Dinas Peternakan Provinsi Jawa Timur mencatat, setidaknya pada tahun 2018 terdapat 234.761 ekor sapi di Kabupaten Malang [1]. Jumlah ini diprediksi masih akan bertambah secara eksponensial sesuai pertumbuhan ekonomi dan penduduk. Sayangnya, pertumbuhan tersebut tidak diiringi oleh kesadaran masyarakat untuk mengolah limbah yang dihasilkan dari aktivitas peternakan. Padahal limbah peternakan berupa padat, cair, dan gas. Limbah cair peternakan belum diolah secara khusus dan dibuang begitu saja ke saluran drainase. Beberapa limbah cair yang dihasilkan dari aktivitas peternakan antara lain adalah ammonia dari urine, bakteri Salmonella sp dari feses serta air bekas mandi hewan ternak [2]. Limbah cair dalam aktivitas peternakan sapi dapat berupa air pencucian ternak dan urin sapi itu sendiri.

Usaha petenakan sapi perlu memerhatikan dampak negatif dari usahanya yakni limbah yang dibuang tanpa proses pengolahan, rawan menyebabkan pencemaran [3]. Jumlah debit limbah cair dalam peternakan pada studi ini menyentuh angka $1,071 \mathrm{~m}^{3} /$ hari dan didapatkan melalui pengukuran secara langsung. Sedangkan parameter yang digunakan untuk menakar kualitas limbahnya adalah Permen. LHK Nomor 11 Tahun 2009 tentang Baku Mutu Air Limbah bagi Usaha dan/atau Kegiatan Peternakan Sapi dan Babi [4]. Diantaranya COD, TSS, pH, NH3-N, dan BOD.

Penelitian ini diharapkan menjadi usaha konkret untuk mereduksi dampak negatif dari limbah cair peternakan, oleh karenanya instalasi pengolahan air limbah (IPAL) harus murah, mudah, dan tepat guna. Upaya pengelolaan limbah peternakan sapi masih belum optimal, baik dari pemerintah maupun masyarakat [5]. IPAL ini menggunakan metode yang terkenal efektif untuk mengurangi kadar limbah dengan parameter seperti di atas yaitu filtrasi dan biofilter anaerob. Material pengisi filter terdiri dari sabut kelapa, pasir, dan arang aktif yang sangat efektif dalam menyerap bau, rasa, serta racun pada air [6]. Sedangkan media sarang tawon digunakan untuk metode biofilter anaerob, karena media ini akan tumbuh mikroorganisme dan akan menguraikan zat organik [7].

Penelitian ini menggunakan tiga alternatif yakni Alternatif A untuk metode filtrasi, Alternatif B untuk metode biofilter, serta Alternatif $\mathrm{C}$ untuk metode kombinasi. Dari ketiga alternatif ini akan dibandingkan mana yang paling efektif untuk mereduksi kandungan limbah cair. Sehingga, model IPAL ini dapat digunakan dan diaplikasikan oleh masyarakat sekitar dan mengurangi tingkat pencemaran yang selama ini dibiarkan begitu saja.

\section{Bahan dan Metode}

\subsection{Bahan}

\section{A. Lokasi Studi}

Penelitian ini berlokasi di Desa Petungsewu Kecamatan Dau, Kabupaten Malang pada sebuah rumah warga yang memiliki peternakan sapi. Kecamatan Dau adalah dataran tinggi dengan wilayah seluas 41,96 km². Topografi kecamatan ini didominasi oleh dataran tinggi dan perbukitan. Ditinjau dari aspek administratif, Kecamatan Dau dikelilingi oleh kecamatan lain. Di utara berbatasan dengan Kota Batu. Di selatan berbatasan dengan Kecamatan Wagir. Kecamatan Lowokwaru di sebelah timur. Serta Kecamatan Gunung Kawi di sebelah barat. Batas administrasi selengkapnya disajikan pada gambar 1.

B. Data penelitian yang dibutuhkan

- Data jumlah sapi yang ada di lokasi

- Data kualitas air limbah

- Data debit per-hari yang dihasilkan 


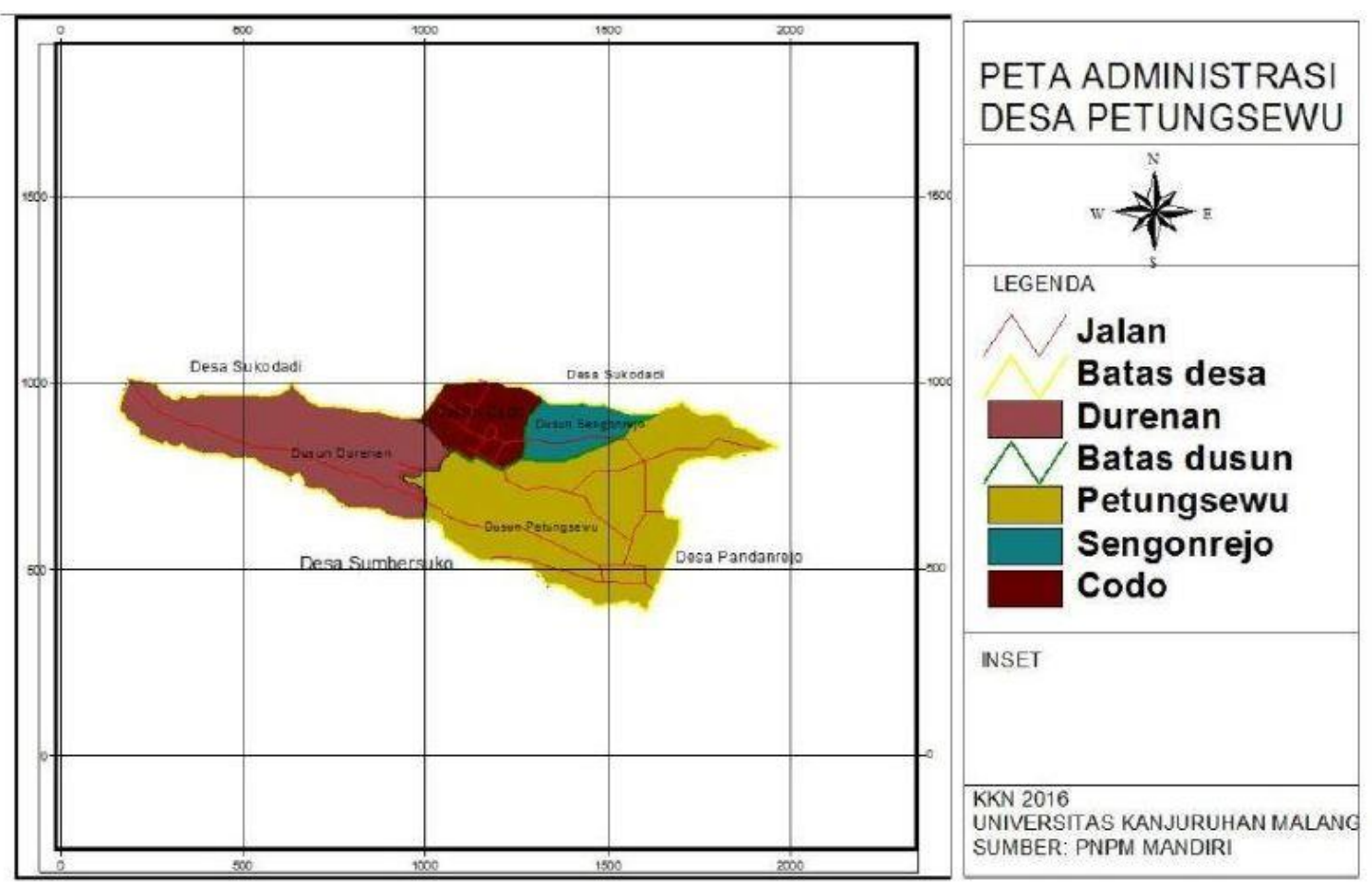

Gambar 1: Peta Administrasi Desa Petungsewu

2.2 Metode Analisis

1. Studi Literatur

2. Pengumpulan Data Perencanaan:

- Data primer berupa kuantitas sapi yang dimiliki peternakan tersebut

- Data yang menunjukkan hasil kualitas air limbah dilakukan secara grab sampling lalu diujikan ke laboratorium dengan parameter dari Kemen. LHK nomor 11 tahun 2009 yaitu BOD, COD, TSS, pH, dan $\mathrm{NH}_{3}-\mathrm{N}$. Grab sampling adalah salah satu teknik dalam pengambilan sampel dimana sumber airnya memiliki banyak kesamaan atribut identitas, misalnya kandungan senyawa kimianya.

- Data debit air limbah didapat dengan cara pengukuran secara langsung melalui bak kontrol sebelum masuk ke IPAL

3. Penentuan, perhitungan, desain, dan pembangunan IPAL mulai dari bak pengendap awal, bak filtrasi, bak biofilter, dan bak pengendap akhir.

4. Pelaksanaan IPAL mulai dari Alternatif A (filtrasi), Alternatif B (biofilter), dan Alternatif C (kombinasi).

5. Penentuan efisiensi dari tiap metode.

6. Mengkalkulasi total Rencana Anggaran Biaya (RAB) yang dibutuhkan untuk kegiatan penelitian ini.

\section{Hasil dan Pembahasan}

\subsection{Perhitungan Debit Limbah}

Perhitungan debit dilakukan secara langsung selama 3 hari berturut-turut. Masing-masing hari 3 percobaan. Debit yang masuk ke bak kontrol dihitung menggunakan alat ukur debit berupa gelas ukur berukuran satu liter dan stopwatch. Untuk detail perhitungan tercantum pada tabel 1. 
Tabel 1: Tabulasi Perhitungan Debit

\begin{tabular}{|c|c|c|c|c|c|c|c|c|c|}
\hline Hari Ke- & & $\mathrm{i}$ & & & ii & & & iii & \\
\hline Percobaan Ke- & 1 & 2 & 3 & 1 & 2 & 3 & 1 & 2 & 3 \\
\hline Waktu (dt) & 80 & 83 & 79 & 81 & 84 & 80 & 79 & 82 & 80 \\
\hline Debit (1/dt) & 0,012 & 0,012 & 0,012 & 0,012 & 0,011 & 0,012 & 0,012 & 0,012 & 0,012 \\
\hline Debit $\left(\mathrm{m}^{3} / \mathrm{dt}\right)$ & $\begin{array}{c}1,25 \mathrm{x} \\
10^{-5}\end{array}$ & $\begin{array}{l}1,20 \\
\times 10^{-5}\end{array}$ & $\begin{array}{l}1,26 \\
\times 10^{-5}\end{array}$ & $\begin{array}{l}1,23 \\
\times 10^{-5}\end{array}$ & $\begin{array}{l}1,19 \\
\times 10^{-5}\end{array}$ & $\begin{array}{l}1,25 \\
\times 10^{-5}\end{array}$ & $\begin{array}{l}1,26 \\
\times 10^{-5}\end{array}$ & $\begin{array}{l}1,21 \\
\times 10^{-5}\end{array}$ & $\begin{array}{l}1,25 \\
\times 10^{-5}\end{array}$ \\
\hline $\begin{array}{l}\text { Rerata debit per } \\
\text { hari(m3/dt) }\end{array}$ & & $1,24 \times 10$ & & & $1,22 \times 10$ & & & $1,24 \times 10$ & \\
\hline $\begin{array}{l}\text { Rerata debit per } \\
\text { hari }(1 / d t)\end{array}$ & & 0,0124 & & & 0,0123 & & & 0,0125 & \\
\hline $\begin{array}{l}\text { Rerata } \\
\text { Keseluruhan (1/dt) }\end{array}$ & & & & & 0,0124 & & & & \\
\hline
\end{tabular}

Rerata debit per hari $=0,0124 \mathrm{l} / \mathrm{dt}$

$\begin{array}{ll}= & 1.071,5541 / \text { hari } \\ = & 1,071 \mathrm{~m}^{3} / \text { hari }\end{array}$

\subsection{Analisis Kualitas Air Limbah}

Dalam perencanaan IPAL, sangat penting untuk mengetahui komponen pencemar yang terdapat pada air limbah. Maka dari itu dikenal istilah baku mutu air sebagai acuan untuk kegiatan pengolahan limbah cair. Dalam studi ini, baku mutu yang digunakan mengacu ke Permen. LHK nomor 11 tahun 2009 tentang Baku Mutu Bagi Usaha dan/atau Peternakan Sapi dan Babi. Sedangkan uji kualitas air limbah dilakukan di laboratorium milik Perum Jasa Tirta I yang berlokasi di Jalan Surabaya, Kota Malang.

Tabel 2: Kualitas Air Limbah

\begin{tabular}{clccc}
\hline No. & Parameter & Satuan & Standar & Hasil \\
\hline \hline 1 & pH & - & $6-9$ & 8,35 \\
2 & BOD & $\mathrm{mg} / 1$ & 100 & 64,27 \\
3 & COD & $\mathrm{mg} / 1$ & 200 & 201,4 \\
4 & TSS & $\mathrm{mg} / 1$ & 100 & 100,1 \\
5 & Amoniak & $\mathrm{mg} / 1$ & 25 & 66,02 \\
\hline
\end{tabular}

Berdasarkan hasil laboratorium pada Tabel 2 dapat dilihat bahwa keseluruhan parameter terbukti melebihi batas ambang baku mutu yang telah ditentukan, kecuali BOD dan $\mathrm{pH}$. Standar pada kolom keempat menyatakan nilai baku mutu, yakni batas kadar maksimal yang diperbolehkan untuk tiap parameter.

\subsection{Penentuan Model IPAL}

3.3.1 Perhitungan Desain Bak Pengendap Awal

- Data

$$
\begin{aligned}
& \text { - Debit }(\mathrm{Q}) \quad=1,071 \mathrm{~m}^{3} / \text { hari } \\
& =0,044 \mathrm{~m}^{3} / \mathrm{jam} \\
& \text { - Kandungan BOD }=64,27 \mathrm{mg} / \mathrm{l} \\
& \text { - Kandungan COD }=201,4 \mathrm{mg} / \mathrm{l} \\
& \text { - Kandungan TSS }=100,1 \mathrm{mg} / \mathrm{l}
\end{aligned}
$$


- Kandungan NH3-N=66,02 mg/l

- Perhitungan

$\mathrm{V}$ diperlukan $=\mathrm{Q}\left(\mathrm{m}^{3} / \mathrm{jam}\right) \times \mathrm{t}(\mathrm{jam})$

Pers. 1

$$
\begin{aligned}
& =0,044 \times 5 \\
& =0,22 \mathrm{~m}^{3}
\end{aligned}
$$

Panjang $(\mathrm{P}) \quad=1 \mathrm{~m}$

Lebar $(\mathrm{L}) \quad=1 \mathrm{~m}$

Kedalaman $(\mathrm{h})=0,6 \mathrm{~m}$

Tinggi jagaan $=0,3 \mathrm{~m}$

Vol. Efektif $\quad=\mathrm{p} \times \mathrm{l} \times \mathrm{h}$

Pers. 2

$$
\begin{aligned}
& =(1 \times 1 \times 0,6) \\
& =0,6 \mathrm{~m}^{3}
\end{aligned}
$$

Syarat: Vol. Bak $\geq$ Vol. Rencana

$$
0,6 \mathrm{~m} 3 \geq 0,22 \mathrm{~m} 3 \text { (Memenuhi) }
$$

- Waktu Tinggal (retention time)

Waktu Tinggal Hidrolik (Hydraulic Retention Time) menyatakan waktu yang dibutuhkan air limbah untuk mengisi IPAL dengan kecepatan konstan per hari [8].

$$
\begin{aligned}
\mathrm{T} & =24 \times \frac{\text { Volume }\left(\mathrm{m}^{3}\right)}{\text { Debit }\left(\frac{\mathrm{m}^{3}}{\text { hari }}\right)} \\
& =24 \times \frac{0,3 \mathrm{~m} 3}{1,071 \mathrm{~m} 3 / \text { hari }} \\
& =13,4 \mathrm{jam}
\end{aligned}
$$

Pers. 3

- Beban Permukaan (surface loading)

$$
\begin{aligned}
\mathrm{SL} & =\frac{\text { Debit limbah cair perhari }}{\text { panjang } \mathrm{x} \text { lebar }} \\
& =\frac{1,071 \mathrm{~m}^{3} / \mathrm{hari}}{1 \mathrm{~m} \times 1 \mathrm{~m}} \\
& =1,071 \mathrm{~m}^{3} / \mathrm{m}^{2} \text {.hari }
\end{aligned}
$$

Pers. 4

\subsubsection{Desain Bak Filtrasi}

- Kriteria Desain dan Dimensi

Bak Filtrasi berdimensi 1, 7 x 1 x 1 ( $\mathrm{p}$ x $1 \times \mathrm{h}$ ) yang berisi 6 buah anyaman kawat besi berbentuk box. Masing-masing box berdimensi 0,5 $\mathrm{m}$ x 0,5 $\mathrm{m}$ x 0,5 $\mathrm{m}$ [9].

- Perhitungan

Flow rate reaktor filtrasi

Debit limbah cair $\quad=1,071 \mathrm{~m}^{3} /$ hari

Retention time $\quad=13,4$ jam

Flow rate $\quad=\frac{\mathrm{Q}\left(\mathrm{m}^{3} / \text { hari }\right)}{\mathrm{t}(\text { jam })}$

Pers. 5

$$
=\frac{1,071}{13,4}
$$$$
=0,07 \mathrm{~m}^{3} / \mathrm{jam}
$$$$
=1,16 \mathrm{l} / \mathrm{menit} \sim 1 \mathrm{l} / \mathrm{menit}
$$

Volume bak minumum $=$ flow rate $\times$ retention time

$$
\begin{aligned}
& =1 \times 13,4 \\
& =13,4 \text { liter }
\end{aligned}
$$


Volume bak rencana $\quad=0,125 \mathrm{~m}^{3}$

Volume bak minimum $\leq$ Volume bak rencana (memenuhi)

3.3.3 Desain Bak Biofilter Anaerob

- Data

Debit (Q)

$$
\begin{array}{ll}
\text { Debit }(\mathrm{Q}) & =1,071 \mathrm{~m}^{3} / \mathrm{hari} \\
& =0,044 \mathrm{~m}^{3} / \mathrm{jam} \\
\text { Kandungan BOD } & =64,27 \mathrm{mg} / \mathrm{l} \\
\text { Kandungan COD } & =201,4 \mathrm{mg} / 1 \\
\text { Kandungan TSS } & =100,1 \mathrm{mg} / 1 \\
\text { Kandungan NH3-N } & =66,02 \mathrm{mg} / 1 \\
\text { Kandungan pH } & =8,3
\end{array}
$$$$
\text { Kandungan COD } \quad=201,4 \mathrm{mg} / \mathrm{l}
$$$$
\text { Kandungan NH3-N }=66,02 \mathrm{mg} / \mathrm{l}
$$

- Kriteria Desain

Tipe

Ketebalan

$=$ Sarang Tawon $($ crossflow $)$

$=0,15-0,23 \mathrm{~mm}$

Material

$=$ PVC Sheet

Berat spesifik

$=30-35 \mathrm{~kg} / \mathrm{m}^{3}$

Luas kontak spesifik

$=150-226 \mathrm{~m}^{2} / \mathrm{m}^{3}$

Diameter lubang

$=2 \times 2 \mathrm{~cm}$

Porositas rongga

$$
=0,98
$$

- Perhitungan

Beban BOD

$$
=\mathrm{Q}\left(\frac{\mathrm{m}^{3}}{\text { hari }}\right) \times \text { kadar BOD }\left(\frac{\mathrm{g}}{\mathrm{m}^{3}}\right)
$$

$=1,071 \mathrm{~m} 3 /$ hari $\times 6,427 \times 10-5 \mathrm{~g} / \mathrm{m} 3$

$=6,883 \times 10-5 \mathrm{~g} / \mathrm{hari}$

Beban COD

$=\mathrm{Q}\left(\frac{\mathrm{m}^{3}}{\text { hari }}\right) \times$ kadar COD $\left(\frac{\mathrm{g}}{\mathrm{m}^{3}}\right)$

Pers. 8

$=1,071 \mathrm{~m}^{3} /$ hari $\times 2,014 \times 10-4 \mathrm{~g} / \mathrm{m}^{3}$

$=2,15610-4 \mathrm{~g} / \mathrm{hari}$

Dimensi

$$
=0,6 \times 1 \times 1(\mathrm{p} \times \mathrm{l} \times \mathrm{t})
$$

$$
=0,6 \mathrm{~m}^{3}
$$

Waktu tinggal (T)

$$
=\frac{\text { Volume bak }}{\text { Debit limbah cair perjam }}
$$

$$
\begin{aligned}
& =\frac{0,6}{0,044} \\
& =13,6 \mathrm{jam}
\end{aligned}
$$

Jumlah media (N)

$$
\begin{aligned}
& =\frac{\text { Volume bak }}{\text { Volume satu buah media (sesuai pasaran) }} \\
& =\frac{0,60 \mathrm{~m}^{3}}{0,36 \mathrm{~m}^{3}} \\
& =1,6 \sim 2 \text { buah media }
\end{aligned}
$$

3.3.4 Desain Bak Pengendap Akhir

- Perhitungan

$$
\begin{array}{ll}
\mathrm{V} \text { diperlukan } & =Q\left(\frac{m^{3}}{\mathrm{jam}}\right) \times t(\mathrm{jam}) \\
& =0,044 \times 5 \\
& =0,22 \mathrm{~m}^{3}
\end{array}
$$




$$
\begin{array}{ll}
\text { Panjang }(\mathrm{P}) & =1,1 \mathrm{~m} \\
\text { Lebar }(\mathrm{L}) & =1 \mathrm{~m} \\
\text { Kedalaman }(\mathrm{h}) & =0,7 \mathrm{~m} \\
\text { Tinggi jagaan } & =0,3 \mathrm{~m} \\
\text { Vol. Efektif } & =\mathrm{p} \times \mathrm{l} \times \mathrm{h} \\
& =1,1 \times 1 \times 3 \\
& =0,33 \mathrm{~m}^{3}
\end{array}
$$

Syarat: Vol. Bak $\geq$ Vol. Rencana

$0,33 \mathrm{~m} 3 \geq 0,22 \mathrm{~m}^{3}$ (Memenuhi)

- Waktu Tinggal

$$
\begin{aligned}
\mathrm{T} & =24 \times \frac{\text { Volume }\left(\mathrm{m}^{3}\right)}{\text { Debit }\left(\frac{\mathrm{m}^{3}}{\text { hari }}\right)} \\
& =24 \mathrm{x} \frac{0,33 \mathrm{~m}^{3}}{1,071 \mathrm{~m}^{3} / \text { hari }} \\
& =7,3 \mathrm{jam}
\end{aligned}
$$

- Beban Permukaan

$$
\begin{aligned}
\text { SL } & =\frac{\text { Debit limbah cair perhari }}{\text { panjang } \times \text { lebar }} \\
& =\frac{1,071 \mathrm{~m}^{3} / \text { hari }}{1,3 \mathrm{~m} \times 1 \mathrm{~m}} \\
& =0,823 \mathrm{~m} 3 / \mathrm{m} 2 \text {.hari }
\end{aligned}
$$

\subsubsection{Desain IPAL}

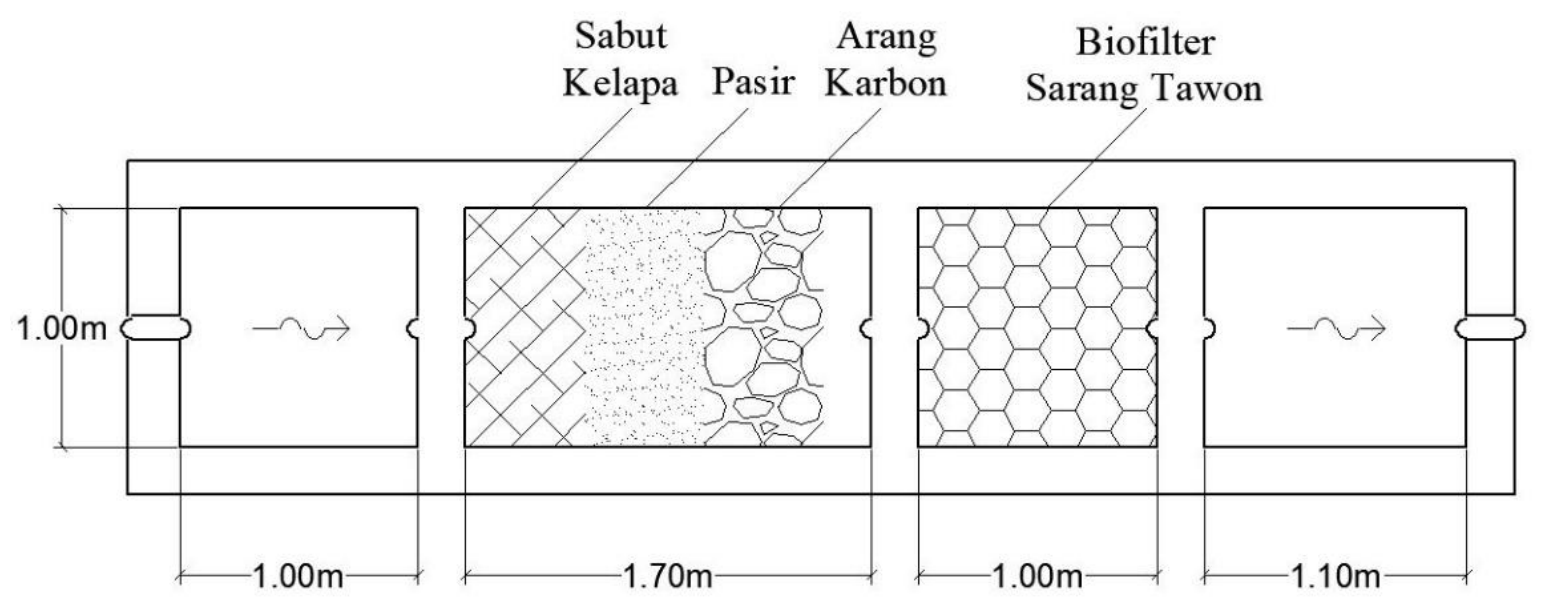

Gambar 2: Nampak Atas Instalasi Pengolah Air Limbah

Setelah melalui serangkaian perhitungan dimensi seperti di atas, maka dimensi IPAL nampak pada gambar 2. Urutan dari kiri ke kanan yaitu bak pengendap awal, bak filtrasi, bak biofilter anaerob, dan bak pengendap akhir.

\subsection{Alternatif Model dan Efisiensinya}

\section{Alternatif A (Filtrasi)}

Air limbah mengalir secara downflow dari bak pengendap awal ke bak filtrasi seperti gambar 3 . Metode filtrasi terdiri dari filter primer (sabut kelapa) yang berfungsi sebagai penyaring utama limbah cair karena kepadatan dan ukurannya sesuai [10], filter sekunder (pasir) berguna untuk untuk memperbaiki kualitas air dan sering digunakan untuk pengolahan air minum (sand filtration). Dikenal sangat efektif dalam menghilangkan kekeruhan [11]. Serta arang karbon yang berperan sebagai adsorben dan menetralisir $\mathrm{pH}$ serta mengurangi bau pada limbah domestik [6]. Hasil pengolahan metode ini secara lengkap pada tabel 3. 


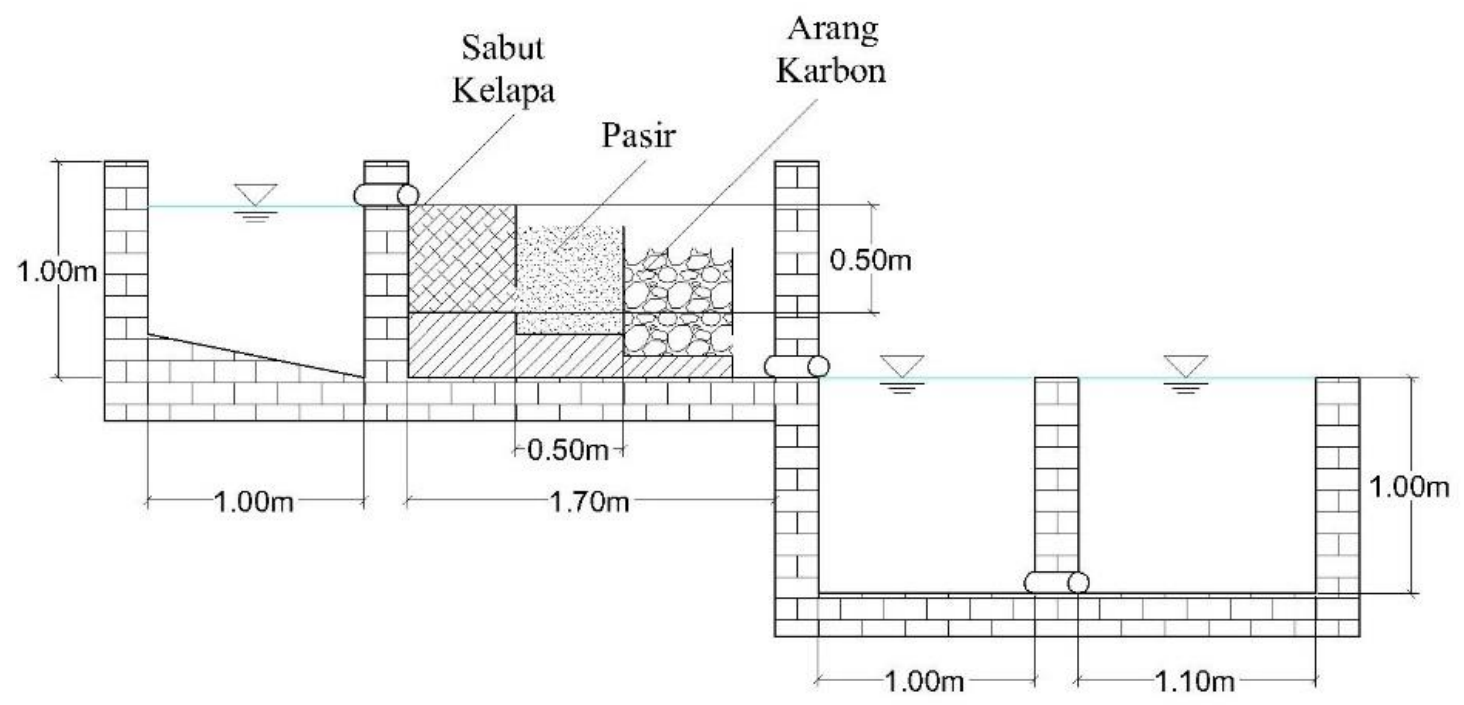

Gambar 3: Potongan Melintang Alternatif A

Tabel 3: Hasil Uji Lab Alternatif A

\begin{tabular}{clccccc}
\hline No. & Parameter & Satuan & Standar & Sebelum & Sesudah & Efisiensi (\%) \\
\hline \hline 1 & pH & - & $6-9$ & 8,35 & 6,98 & - \\
2 & BOD & $\mathrm{mg} / 1$ & 100 & 64,27 & 18,05 & 71,92 \\
3 & COD & $\mathrm{mg} / 1$ & 200 & 201,4 & 64 & 68,22 \\
4 & TSS & $\mathrm{mg} / 1$ & 100 & 100,1 & 21 & 79,02 \\
5 & NH3-N & $\mathrm{mg} / \mathrm{l}$ & 25 & 66,02 & 2,86 & 95,67 \\
\hline
\end{tabular}

Efisiensi $=\frac{\text { sebelum-sesudah }}{\text { sebelum }} \times 100$

2. Alternatif B (Biofilter Anaerob)

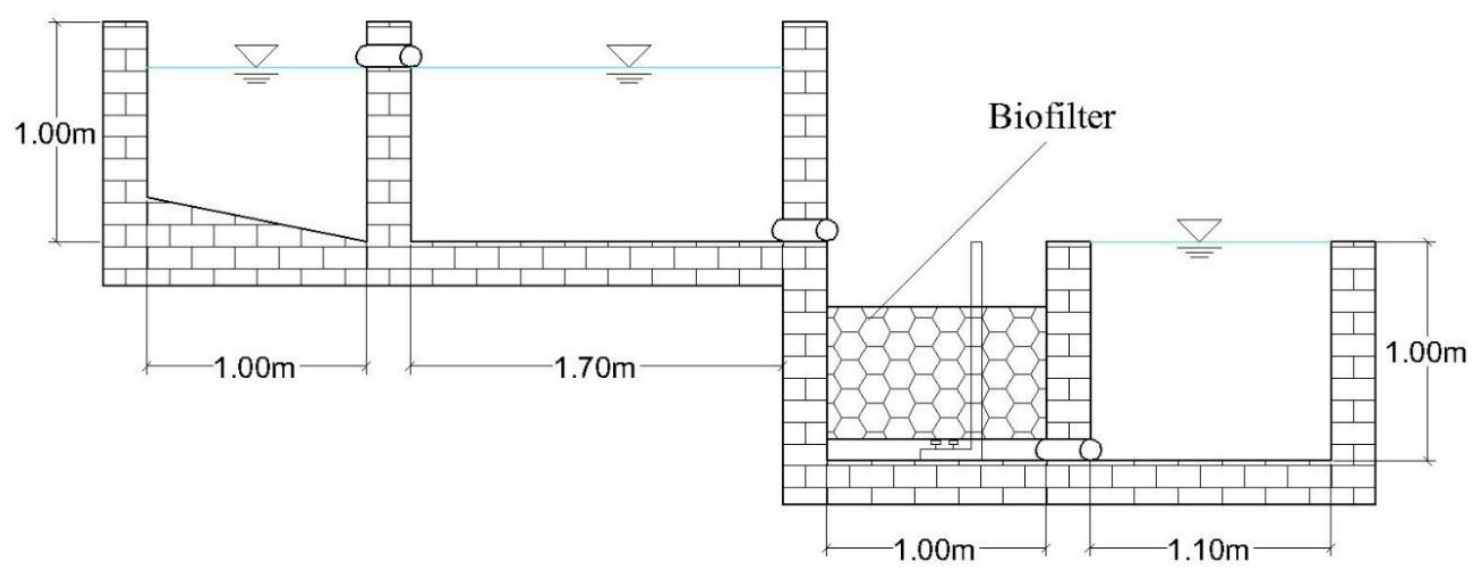

Gambar 4: Potongan Melintang Alternatif B

Biofilter anaerob sangat umum digunakan untuk pengolahan limbah domestik [12]. Dalam penelitian ini, aliran air mengalir secara downflow hingga melalui biofilter anaerob seperti pada gambar 4 di atas, lalu didiamkan selama kurun waktu yang tertera pada perhitungan retention time. Kualitas air yang dihasilkan adalah sebagai berikut. 
Tabel 4: Uji Hasil Lab Alternatif B

\begin{tabular}{clccccc}
\hline No. & Parameter & Satuan & Standar & Sebelum & Sesudah & Efisiensi (\%) \\
\hline \hline 1 & pH & - & $6-9$ & 8,35 & 6 & - \\
2 & BOD & $\mathrm{mg} / 1$ & 100 & 64,27 & 26,81 & 58,29 \\
3 & COD & $\mathrm{mg} / 1$ & 200 & 201,4 & 80,93 & 59,82 \\
4 & TSS & $\mathrm{mg} / 1$ & 100 & 100,1 & 93 & 7,09 \\
5 & NH3-N & $\mathrm{mg} / 1$ & 25 & 66,02 & 0,1724 & 99,74 \\
\hline
\end{tabular}

Efisiensi $=\frac{\text { sebelum-sesudah }}{\text { sebelum }} \times 100$

3. Alternatif C (Kombinasi)

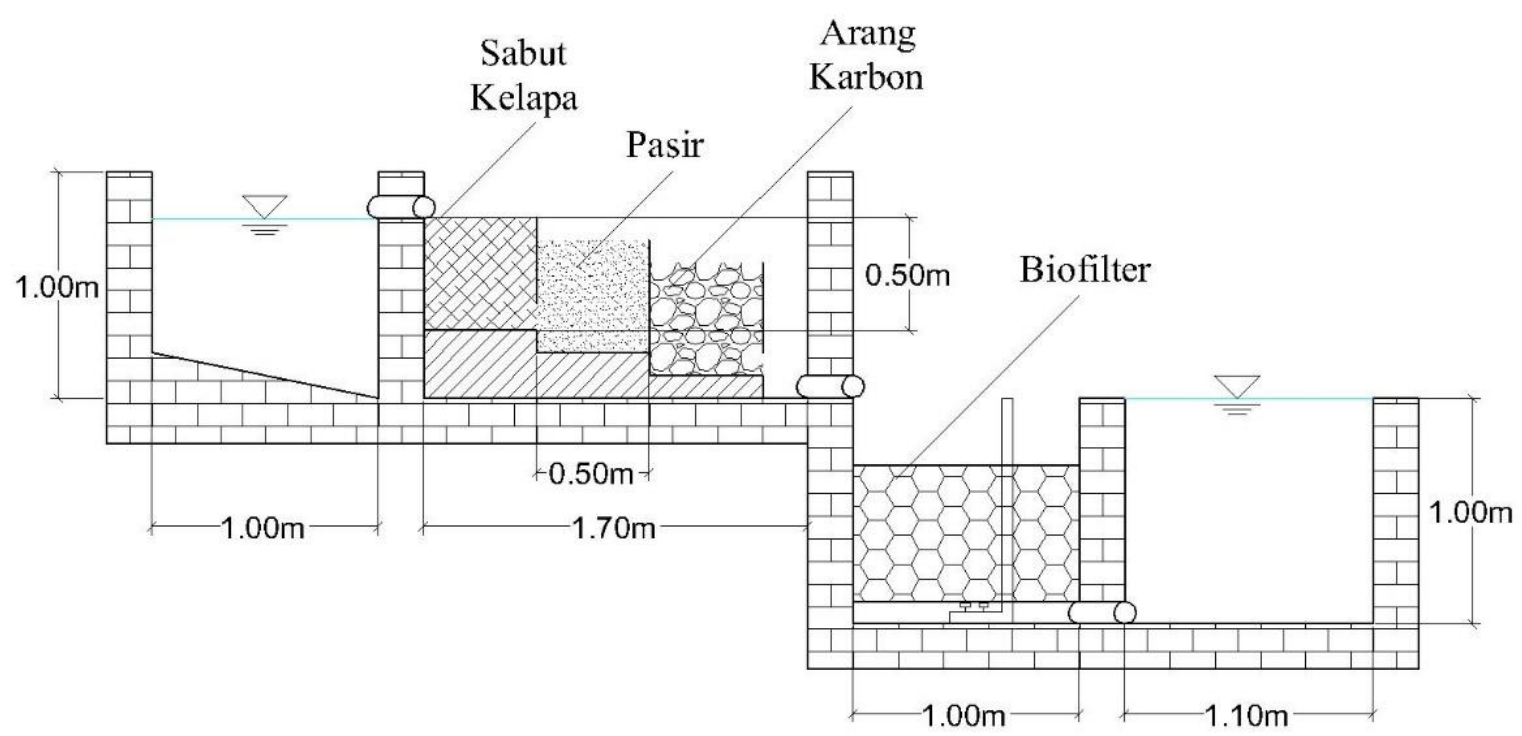

Gambar 5: Potongan Melintang Alternatif C

Alternatif $\mathrm{C}$ adalah kombinasi dari kedua metode sebelumnya. Air limbah mengalir downflow dari bak pengendap awal, menuju bak filtrasi (gambar 5). Setelah dari bak filtrasi dialirkan lagi menuju bak biofilter. Lalu berakhir di bak penfendap akhir. Berangkat dari sebuah asumsi sederhana, apakah jika kedua metode dalam mengolah limbah digabungkan akan menghasilkan sebuah hasil yang optimal. Hasil selengkapnya disajikan dalam tabel di bawah ini.

Tabel 5: Hasil Uji Lab Alternatif C

\begin{tabular}{clccccc}
\hline No. & Parameter & Satuan & Standar & Sebelum & Sesudah & Efisiensi (\%) \\
\hline \hline 1 & pH & - & $6-9$ & 8,35 & 6 & - \\
2 & BOD & $\mathrm{mg} / 1$ & 100 & 64,27 & 7,85 & 87,79 \\
3 & COD & $\mathrm{mg} / 1$ & 200 & 201,4 & 25,31 & 87,43 \\
4 & TSS & $\mathrm{mg} / 1$ & 100 & 100,1 & 6 & 94,01 \\
5 & NH3-N & $\mathrm{mg} / 1$ & 25 & 66,02 & 0,11 & 99,83 \\
\hline
\end{tabular}

Efisiensi $=\frac{\text { sebelum-sesudah }}{\text { sebelum }} \times 100$

3.5 Rekapitulasi Hasil Pengolahan Limbah

Dari ketiga metode yang telah dilaksanakan, masing-masing menunjukkan hasil efisiensi pengurangan kadar polutan yang cukup signifikan. Untuk itu masing-masing alternatif dihitung rerata 
efisiensinya agar dapat diketahui metode mana yang paling efektif. Hasil perbandingan secara detail disajikan di tabel 6 .

Tabel 6: Rekapitulasi

\begin{tabular}{clccc}
\hline \multirow{2}{*}{ No. } & \multirow{2}{*}{ Parameter } & \multicolumn{3}{c}{ Efisiensi (\%) } \\
\cline { 3 - 5 } & & Alternatif A & Alternatif B & Alternatif C \\
\hline 1 & pH & - & - & - \\
2 & BOD & 71,92 & 58,29 & 87,79 \\
3 & COD & 68,22 & 59,82 & 87,43 \\
4 & TSS & 79,02 & 7,09 & 94,01 \\
5 & Amoniak & 95,67 & 99,74 & 99,83 \\
\hline & Rerata & 78,71 & 56,23 & 92,26 \\
\hline
\end{tabular}

Berdasarkan tabel 6, maka urutan alternatif metode yang paling efisien berturut-turut:

1. Alternatif C (rerata $92,26 \%$ )

2. Alternatif A (rerata $78,71 \%$ )

3. Alternatif B (rerata $56,23 \%$ )

3.6 Rencana Anggaran Biaya (RAB)

RAB untuk pembangunan IPAL peternakan sapi terdiri dari 5 macam pekerjaan utama. Dimulai dari pekerjaan persiapan, tanah, struktur, perpipaan, dan lain-lain. Dalam RAB sudah terangkum seluruh kebutuhan untuk ketiga alternatif. Selengkapnya disajikan dalam tabel 7 berikut ini.

Tabel 7: Rincian RAB

\begin{tabular}{|c|c|c|c|c|c|}
\hline No. & Uraian Pekerjaan & Satuan & Volume & $\begin{array}{l}\text { Harga Satuan } \\
\text { (Rp) }\end{array}$ & $\begin{array}{c}\text { Jumlah } \\
\text { Harga (Rp) }\end{array}$ \\
\hline 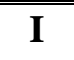 & Pekerjaan Persiapan & & & & \\
\hline \multirow[t]{2}{*}{1.} & Pembersihan Lahan & $\mathrm{m}^{2}$ & 5,00 & 14.921 & 74.605 \\
\hline & Sub Total & & & & 74.605 \\
\hline II & Pekerjaan Tanah & & & & \\
\hline \multirow[t]{2}{*}{1.} & Pekerjaan Galian & $\mathrm{m}^{3}$ & 6,00 & 68.136 & 408.816 \\
\hline & Sub Total & & & & 408.816 \\
\hline III & Pekerjaan Struktur & & & & \\
\hline 1. & Pemasangan Dinding Bata & $\mathrm{m}^{2}$ & 21,00 & 216.790 & 4.552 .590 \\
\hline 2. & Pekerjaan Plat Lantai & $\mathrm{m}^{2}$ & 3,00 & 1.149 .604 & 3.448 .812 \\
\hline 3. & Pekerjaan Kolom Praktis & $\mathrm{m}^{2}$ & 6,00 & 197.038 & 1.182 .280 \\
\hline 3. & Pekerjaan Plesteran & $\mathrm{m}^{2}$ & 21,00 & 58.680 & 1.232 .280 \\
\hline 4. & Pekerjaan Acian & $\mathrm{m}^{2}$ & 21,00 & 35.552 & 746.592 \\
\hline
\end{tabular}


Lanjutan Tabel 7: Rincian RAB

\begin{tabular}{clcccc}
\hline & Sub Total & & & & $\mathbf{1 1 . 4 9 0 . 2 6 7}$ \\
\hline IV & Pekerjaan Perpipaan & & & & \\
1. & Pemasangan Pipa 4” & m' & 10,00 & 65.656 & 656.560 \\
2. & Pembuatan Bak Kontrol & buah & 1,00 & 202.685 & 202.685 \\
\hline & Sub Total & & & & $\mathbf{8 5 9 . 2 4 5}$ \\
\hline V & Pekerjaan Lain-Lain & & & & \\
1. & Pembuatan Box Filtrasi & buah & 6,00 & 100.000 & 600.000 \\
2. & Media Sarang Tawon & buah & 2,00 & 75.000 & 150.000 \\
3. & Bahan Pengisi Filtrasi & buah & 1,00 & 120.000 & 120.000 \\
\hline & Sub Total & & & & $\mathbf{8 7 0 . 0 0 0}$ \\
\hline
\end{tabular}

\section{Kesimpulan}

Setelah melalui tahapan demi tahapan uji coba metode Instalasi Pengolahan Air Limbah (IPAL) peternakan sapi. Ketiga metode yakni Alternatif A (filtrasi), Alternatif B (biofilter anaerob), dan Alternatif C (kombinasi) menunjukkan hasil yang memuaskan. Kadar pencemar dapat tereduksi hingga 99,83\% atau nyaris sempurna. Dari ketiga alternatif yang telah dibahas, urutan altenatif yang paling efektif dan efisien dalam mereduksi kadar polutan pada limbah adalah Alternatif C $(92,26 \%)$, Alternatif A $(78,71 \%)$, dan Alternatif B $(56,23 \%)$. Biaya yang dibutuhkan untuk pembangunan IPAL peternakan sapi sejumlah Rp13.702.933,00. Pembangunan IPAL ini bukanlah upaya final, metode yang lebih murah dan lebih efektif masih banyak yang bisa dikembangkan dan dielaborasi. Selain itu, pemilik perlu melaksanakan penjadwalan dalam perawatan IPAL agar manfaatnya dapat dinikmati secara berkelanjutan.

\section{Ucapan Terima Kasih}

Ucapan terima kasih disampaikan kepada Ibu Dian Chandrasasi, ST., MT. sebagai dosen teknik pengairan yang telah memfasilitasi penelitian ini secara penuh. Mulai dari penentuan lokasi, data kualitas air, hingga bangunan fisik Instalasi Pengolah Air Limbah (IPAL) beserta alat dan bahannya.

\section{Daftar Pustaka}

[1] Dinas Peternakan Provinsi Jatim, "Populasi Ternak Menurut Kabupaten/Kota dan Jenis Ternak di Provinsi Jawa Timur,” 2019.

[2] S. Rachmawati, "Upaya pengelolaan lingkungan usaha peternakan ayam," Wartazoa, vol. 9, no. 2, pp. $73-80 ., 2000$.

[3] Y. K. Bintang, D. Chandrasasi, and R. Haribowo, "STUDI EFEKTIFITAS DAN KINERJA INSTALASI PENGOLAHAN AIR LIMBAH ( IPAL ) PADA PETERNAKAN SAPI SKALA RUMAH TANGGA,”J. Tek. Pengair., vol. 10, no. 1, pp. 51-58, 2019.

[4] Kementerian Lingkungan Hidup, "Keputusan Menteri Lingkungan Hidup No. 11 Tahun 2009 Tentang Baku Mutu Air Limbah Bagi Usaha Peternakan Sapi/Babi,” 2009.

[5] F. R. Widyastuti, "Upaya Pengelolaan Lingkungan Usaha Peternakan Sapi di Kawasan 
Usahatani Terpadu Bangka Botanical Garden Pangkalpinang," in Prosiding Seminar Nasional Pengelolaan Sumber Daya Alam dan Lingkungan 2013, 2013, no. 237, pp. 81-85.

[6] N. Salim, N. S. Rizal, and R. Vihantara, "Komposisi Efektif Batok Kelapa sebagai Karbon Aktif untuk Meningkatkan Kualitas Airtanah di Kawasan Perkotaan," MEDIA Komun. Tek. SIPIL, vol. 24, no. 1, p. 87, 2018, doi: 10.14710/mkts.v24i1.18865.

[7] N. I. Said, "TEKNOLOGI BIOFIL TER ANAEROB-AEROB TERCELUP UNTUK PENGOLAHAN AIR LIMBAH DOMESTIK," Kelompok Teknol. Pengelolaan Air Bersih dan Limbah Cair. Direktorat Teknol. Lingkung. BPPT, no. 1989, pp. 160-169, 2010.

[8] S. A. Siregar, "Instalasi Pengolahan Air Limbah," Seri Sanitasi Lingkung. Pedoman Tek. Dengan Sist. Biofilter Anaerob Aerob Pengolah. Air Limbah Instal. Pada Fasilitas Pelayanan Kesehat. Kementeri., vol. 24, no. 2, pp. 1-9, 2011.

[9] S. Irmanto, "Optimasi Penurunan COD, BOD, dan TSS Limbah Cair Industri Etanol (vinasse) PSA Palimanan Dengan Metode Multi Soil Layering (MSL)," J. Tek. Kim. Unsoed, pp. 131$141,2012$.

[10] F. Kumalasari and Y. Satoto, Teknik Praktis Mengolah Air Kotor Menjadi Air Bersih Hingga Layak di Minum. Bekasi: Laskar Aksara, 2011.

[11] D. Maryani and A. Masduqi, "Pengaruh Ketebalan Media dan Rate filtrasi pada Sand Filter dalam Menurunkan Kekeruhan dan Total Coliform," J. Tek. POMITS, vol. 3, no. 2, pp. 1-6, 2014.

[12] BPPT, "Contoh Perencanaan dan Pembangunan IPAL Domestik Kapasitas 150 m3 Per Hari," in Perencaan IPAL Domestik, 2010, pp. 233-285. 